\title{
REGIONAL ECONOMY WITHIN THE CONTEXT OF BIOECONOMY
}

\author{
Y. Yarkova, B. Stoykova, N. Markov*, M. Bankova \\ Department of Regional Development, Faculty of Economics, Trakia University, Stara Zagora, \\ Bulgaria
}

\begin{abstract}
The importance of bioeconomy for society and its development in the $21^{\text {st }}$ century creates responsibility to monitor how national and regional economies in Europe respond to the cause called bioeconomy. The report aims to trace the change in the sectoral structure of the economy in the NUTS 2 regions in Bulgaria, paying particular attention to those who are primary consumers and producers of biological resources. For the objective and the tasks of the present study methodology for structural analysis based on aggregated nomenclature A10 from the Classification of Economic Activities (NACE.BG 2008) is applied, as well as other economic and statistical methods of analysis - growth rate and accretion, localization quotient and concentration. The indicators used are the number of employees per sector and share in the GVA of each region for four selected economic activities. The results of the study refer to the change in their localization benefits by regions for the period 2007-2016. The conclusions point to the need for a targeted support approach for identifying and developing sectoral and technological niches of bioeconomy that are promising for the respective region as well the need to develop regional statistical information for the bioeconomic sector.
\end{abstract}

Key words: regional economy, NUTS2, structure, bioeconomy, Bulgaria

\section{INTRODUCTION}

The strategy adopted by the European Commission in 2012 to drive the European economy towards more intensive and sustainable use of renewable resources, known as "Innovations for sustainable growth: a bioeconomy for Europe" (COM(2012)60 (1) and revised in 2017 (SWD(2017)374 (2) sets goals that are implemented in three aspects: developing new technologies and processes; developing markets; close cooperation between authorities and institutions that develop policies involving all stakeholders. The current (2019) year is expected to launch 14 specific actions to address key challenges for European citizens based on a sustainable bioeconomy (European Commission 2018). However, Denis de Rougemont (3) argues that the state is too small to solve the global problems of our time and too big to know the problems of local communities and reminds in the "The Future is our Affair" the role of regional economy and

\footnotetext{
*Correspondence to: Nedelin Markov,

Department of Regional Development, Faculty of E conomics, Trakia University, Stara Zagora, Bulgari a,n_markov@uni-sz.bg
}

its management to effectively improve the quality of life of communities.

Both on the basis of theoretical considerations and after studies on the impacts of bioeconomy on a regional level, it is common ground that regional bioeconomy is of great importance for generating positive socio-economic impacts, especially in sparsely populated peripheral resource areas $(4,5)$. The importance of bioeconomy to society and its development in the $21^{\text {st }}$ century creates a responsibility to track how national and regional economies in Europe respond to the cause called bioeconomy. Moreover, is there a combination of the biophysical perspective of economics with intelligent and green growth? Expectations are also tied to the pursuit of social and territorial cohesion.

The present study is part of a larger study, which includes analysis of the dynamics of the bioeconomic sectors of regions at a different level in Bulgaria, conducted within the framework of the National Scientific Program "Healthy Foods for a Strong Bioeconomy and Quality of Life". This report looks at the 
change in the sectoral structure of the economy of Level 2 regions, paying particular attention to those that are primary users and producers of biological resources as well as those that are their secondary users and/or holders of functions and processes with a direct and/or indirect link to the principles and innovative achievements of bioeconomy.

\section{METHODS}

Bioeconomy covers all sectors and systems that rely on biological resources (animal, plant biomass, micro-organisms, including organic waste), their functions and principles (6). As one of the first countries with regional biostatistics, Sweden offers a similar definition (7), "An economy based on sustainable production of biomass to enable increased use within a number of different sectors of society. The objective is to reduce climate effects and the use of fossil-based raw materials. An increased added value for biomass materials, concomitant with a reduction in energy consumption and recovery of nutrients and energy as additional end products. The objective is to optimize the value and contribution of ecosystem services to the economy." Database Bioeconomy Products and Processes defines nine categories of bioeconomy products (conventional biofuels, biofuels, bioplastics, industrial parts, green chemicals, lubricants, home care, fiber and food and feed additives) (8). Some industries belong one hundred percent to the bioeconomy, that is, what these industries create, directly or indirectly, contributes to the production or adding value of biomass, such as agriculture, forestry, fishing, food production, tobacco, wood, paper, paper pulp, etc. Other industries partly produce goods or services that are related to the use of biomass (plants, forest resources, animals, fish, etc.) and to integrate them into surveys, statistical surveys on a micro level are needed - enterprises determined to be bioeconomic.

This study was conducted at NUTS 2 level in Bulgaria and it was possible to use the aggregate A10 nomenclature of the Classification of Economic Activities (NACE.BG 2008) from the National Statistical Institute (NSI). Within this sectoral aggregation, three groups of sectors with a different role for societal needs in terms of bioeconomy have been included: a) primary consumers and/or producers of biological resources (Agriculture, Forestry and Fisheries, Processing industry, Industry (excluding
Processing industry); b) secondary users of biological and/or biophysical products in the context of the circular economy (Construction; Trade, transport, hotel- and restaurant-keeping; Creation and dissemination of information and creative products, telecommunications); c) sectors creating environment for bioeconomic activity (Financial and insurance activities; Professional activities and scientific research, administrative and auxiliary activities; State government, education, human health care and social work; Culture, sports and entertainment, repair of household items and other activities). The present report reflects the structure of the regional economy at NUTS2 level in Bulgaria in 2016, focusing on sectors in group (a). Considering that there is potential in the sector of Culture, sports and entertainment, repair of household items and other activities, related to the goals of the bioeconomy strategy, the authors trace its regional dynamics as well. Economic and statistical methods of analysis are applied - structural analysis, growth rate and accretion, localization and concentration quotient. The structure of the regional economy is based on the share of the employed, and for the agrarian sector its contribution to the gross value added (GVA) of each region has also been taken into account. Territorial distributions of data have been classified under the NUTS2 territorial units of the 6 statistical regions: North-West, North Central, North-East, South-East, South-West, South Central. The time period covers 10 years from the accession of Bulgaria to the EU. The data from the last year of the provided regional statistics (2016) have been compared with the ones in 2007, when the so-called "Cologne paper" (conference "En Route to the Knowedge-Based Bio-Economy", 2007) dates back to.

\section{RESULTS}

Table 1 presents the breakdown of the employed by sectors in the country and the six NUTS 2 regions in 2016. Both for the national and the regional economy it is characteristic that the share of group (a) industries is the leading one and in three of the six regions it exceeds 50\% (NWR-52.07\%, NCR-52.29\%, SCR-51.34\%). Given that in this group of industries employment in Agriculture, Forestry and Fisheries and Processing industry (Figure 1) is the leading one, we can note the substantial economic fact that in almost all regions of the country (except the region with the capital city county) the bioeconomic potential of economy is obvious. 
Table 1. Structure of regional economy (number of employees), 2016 NUTS2

\begin{tabular}{|c|c|c|c|c|c|c|c|c|c|c|c|c|}
\hline $\begin{array}{l}\stackrel{0}{0} \\
\stackrel{0}{00} \\
\stackrel{0}{\alpha}\end{array}$ & $\underset{\nu}{\stackrel{\Xi}{\Xi}}$ & 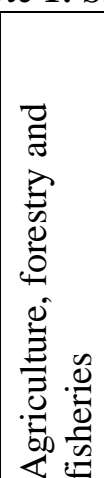 & 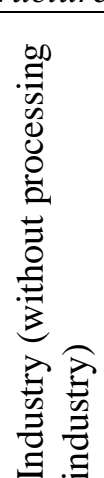 & 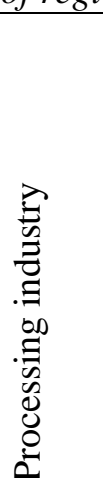 & 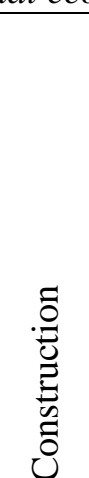 & 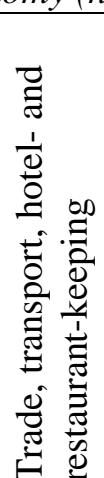 & 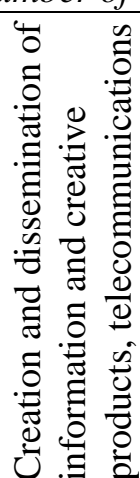 & 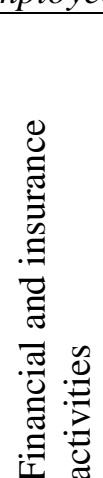 & 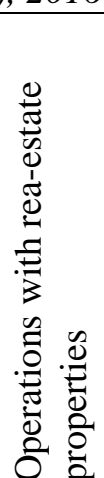 & 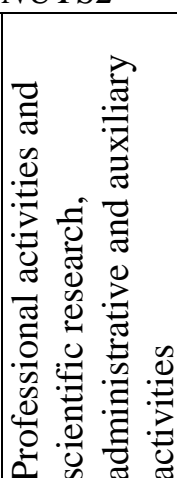 & 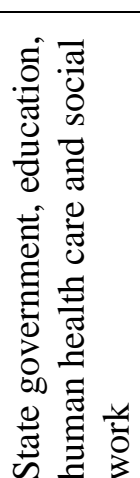 & 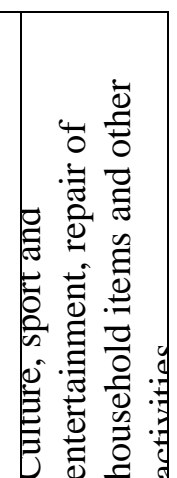 \\
\hline \multirow[t]{2}{*}{ Bukgaria } & 2007 & 19,42 & 3,02 & 19,41 & 6,74 & 23,24 & 1,83 & 1,38 & 0,56 & 5,37 & 16,43 & 2,60 \\
\hline & 2016 & 18,05 & 2,65 & 17,57 & 5,06 & 25,62 & 2,60 & 1,88 & 0,76 & 7,05 & 15,71 & 3,05 \\
\hline \multirow{2}{*}{ NWR } & 2007 & 26,41 & 4,41 & 21,14 & 4,55 & 15,69 & 1,33 & 0,56 & 0,19 & 2,71 & 20,00 & 3,01 \\
\hline & 2016 & 28,60 & 3,29 & 20,18 & 3,16 & 19,44 & 0,44 & 0,66 & 0,44 & 2,81 & 19,08 & 1,90 \\
\hline \multirow[b]{2}{*}{ NCR } & 2007 & 25,97 & 2,48 & 24,62 & 4,71 & 19,21 & 1,47 & 0,69 & 0,22 & 2,74 & 15,67 & 2,22 \\
\hline & 2016 & 26,56 & 1,80 & 23,93 & 3,43 & 21,31 & 0,61 & 0,62 & 0,47 & 3,30 & 15,55 & 2,42 \\
\hline \multirow{2}{*}{ NER } & 2007 & 23,17 & 2,25 & 16,09 & 7,61 & 25,12 & 1,68 & 0,74 & 0,45 & 4,46 & 16,32 & 2,11 \\
\hline & 2016 & 24,07 & 2,05 & 13,59 & 6,12 & 27,25 & 1,05 & 1,10 & 0,78 & 6,00 & 15,05 & 2,94 \\
\hline \multirow{2}{*}{ SER } & 2007 & 25,46 & 4,88 & 18,60 & 7,42 & 21,71 & 1,44 & 0,55 & 0,30 & 3,21 & 14,47 & 1,96 \\
\hline & 2016 & 21,15 & 4,25 & 19,06 & 5,60 & 25,95 & 0,54 & 0,65 & 0,72 & 4,19 & 15,13 & 2,76 \\
\hline \multirow{2}{*}{ SWR } & 2007 & 7,70 & 2,44 & 16,31 & 8,20 & 28,97 & 2,60 & 2,95 & 1,10 & 9,65 & 16,64 & 3,44 \\
\hline & 2016 & 6,12 & 2,48 & 12,77 & 5,91 & 29,42 & 5,96 & 3,91 & 1,08 & 12,39 & 15,94 & 4,02 \\
\hline \multirow{2}{*}{ SCR } & 2007 & 25,25 & 2,69 & 23,54 & 5,49 & 19,60 & 1,39 & 0,54 & 0,29 & 3,11 & 16,18 & 1,92 \\
\hline & 2016 & 25,29 & 2,42 & 23,63 & 4,09 & 22,16 & 0,75 & 0,63 & 0,49 & 3,51 & 14,69 & 2,34 \\
\hline
\end{tabular}

Source: Own calculations from NSI data, Macroeconomic statistics, Employees - regional level, GDP_2.1.4.xls (2016), Infostat (2007)

The analysis of the dynamics of sectoral group (a) and "Culture, sports and entertainment, repair of household items and other activities" for the period 2007-2016 (Figure 2) shows that in most regions (four out of six) growth in the share of sectors "Agriculture, forestry and fisheries" and "Culture, sports and entertainment, repair of household items and other activities" was present. However, the increase of the share of "Agriculture, forestry and fisheries" is with decrease in the absolute number of employees in this sector as a result of a decrease in the total number of the population and the population of working age (NSI), therefore the increase of the share is rather a result of a faster reduction of employees in some other sectors for that period. However, we should not miss an important fact the share of young people (up to 35 years) in agriculture has grown from $19 \%$ to $21.5 \%$ for the period 2008-2018 (9). This is mainly due to the incentives for that group of farmers. Moreover, in the future agricultural policy, at least $2 \%$ of the annual national direct payments for each Member State must be dedicated to generational renewal, compared to the current expenditure of $0.8 \%$ (Words of Agriculture Commissioner Phil Hogan to the Presidium of the European Council of Young Farmers (CEJA) on 28 May 2019). This amount should either be provided in the form of additional income support (under Pillar 1) and / or as a grant (Pillar 2) aimed at setting up new farms by young farmers.In the other sector "Culture, sports and entertainment, repair of household items and other activities", the observed growth in the structure of the regional economy is accompanied by an increase in the number of employees. Although at this stage the share of this sector is low (ranging from $1.9 \%$ to $4.02 \%$ in 2016), its expansion on a relative and absolute scale confirms the need to use its potential to implement the priorities for building sustainable bioeconomy on a regional level.

The reduction of the role of Industry (excluding processing industry) (except for one region) and the Processing industry (except for two regions) is expressed both in their relative share and in the absolute number of employees. Undoubtedly, the available potential for deploying bio-based activities in these sectors has been limited. This is a period of deepening problems in the demographic characteristics of the population (number and structure), which would be hard to compensate by the enhanced policy and regulatory basis explaining and supporting the activity of the bioeconomic sectors. 
YARKOVA Y., et al.

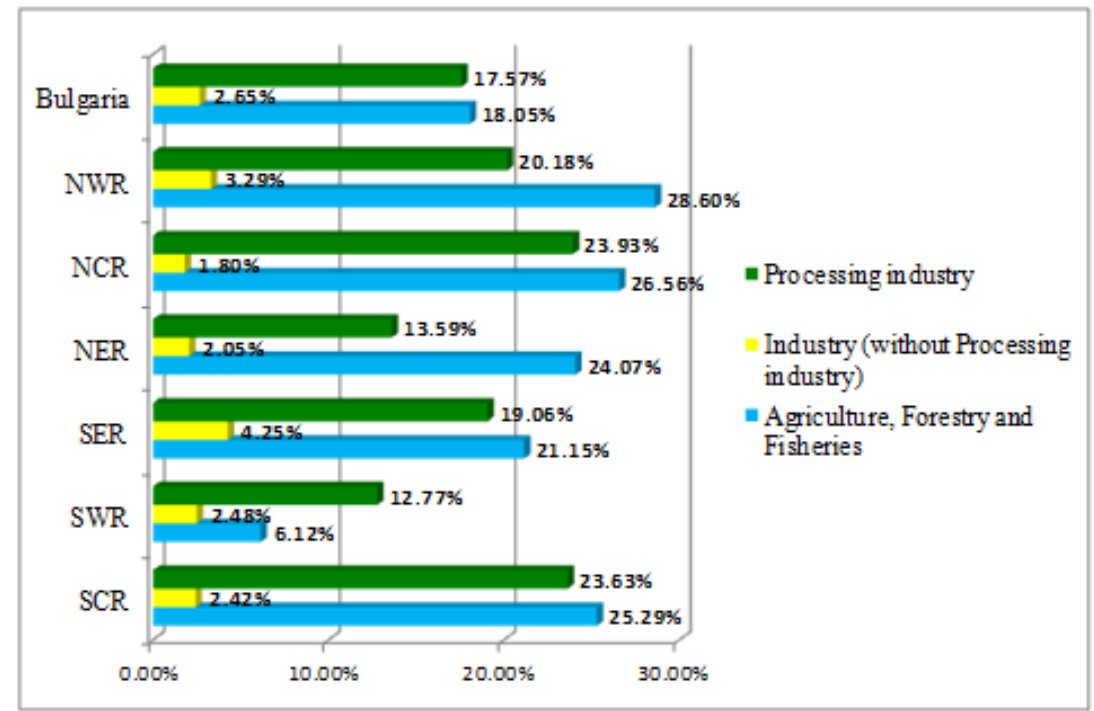

Figure 1. Structure of employees by sectors in sector group (a)

Source: Own graphic presentation from data by NSI, Macroeconomic statistics, Employees regional level, GDP_2.1.4.xls (2016), Infostat (2007)

The share of the leading sector in terms of employment (agricultural) in all regions has the lowest share in GVA compared to the Industry and Services sectors. Its contribution to the region based GVA in 2016 varies from $1.44 \%$ in the SWR to $13.24 \%$ in the NWR), with an average of $4.7 \%$ for the country (Table 2). Let us not forget that there is a great potential here to create added value in the sector, namely through bioeconomy.

Table 2 presents the ranking of areas by indicator share of the agrarian sector in GVA. The ranking of the individual regions according to the share of the agrarian sector in the established GVA has not changed, with the exception of the SCR, which falls back from third to fourth position, due to the contraction of
GVA in the agricultural sector by almost 2.5 percentage points. This is a very serious omission of the opportunity to expand the bioeconomy, with recorded growth in demand for organic food in large cities. According to Aleksiev et al. (10) there is already a clear breakthrough in the organic food market, including not only households with the highest incomes but also middle-income households. There is an increase in the share of the agricultural sector in GVA in the NWR and NER. This is one of the signals that in these regions it is necessary to explore in more depth the potential for more intensive deployment of the relevant components of bioeconomy and to develop measures for its implementation.

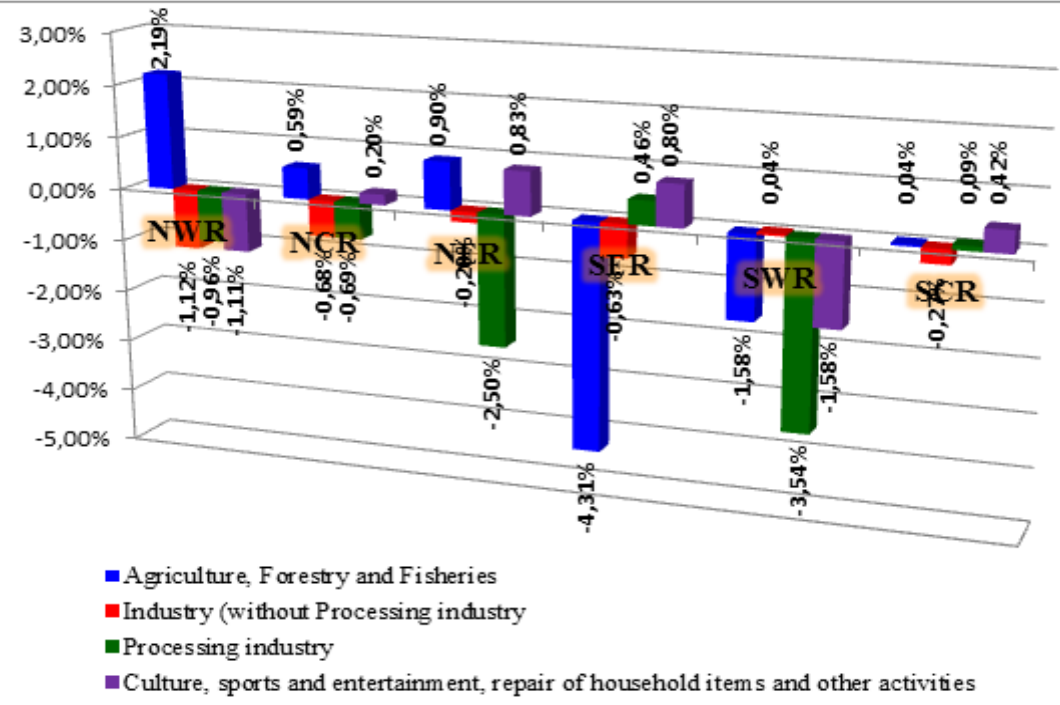

Figure 2. Accretion rate of the share employees in selected sectors percentage points 2016 to 2007 Source: Own graphic presentation from data by NSI, Macroeconomic statistics, Employed people regional level, GDP_2.1.4.xls (2016), Infostat (2007) 
YARKOVA Y., et al.

Table 2. Ranking of NUTS 2 regions, according to the share of the Agricultural sector in GVA

\begin{tabular}{|l|c|l|l|l|}
\hline \multirow{2}{*}{ Rank } & \multicolumn{2}{|c|}{2007} & \multicolumn{2}{c|}{2016} \\
\cline { 2 - 5 } & Agricultural & \multicolumn{1}{c|}{ Region } & Agricultural & \multicolumn{1}{c|}{ Region } \\
\hline 1 & $10,90 \%$ & NWR & $13,24 \%$ & NWR \\
\hline 2 & $9,27 \%$ & NCR & $9,29 \%$ & NCR \\
\hline 3 & $9,25 \%$ & SCR & $7,19 \%$ & NER \\
\hline 4 & $6,71 \%$ & NER & $6,86 \%$ & SCR \\
\hline 5 & $6,58 \%$ & SER & $5,25 \%$ & SER \\
\hline 6 & $5,48 \%$ & BULGARIA & $4,70 \%$ & BULGARIA \\
\hline 7 & $1,99 \%$ & SWR & $1,44 \%$ & SWR \\
\hline
\end{tabular}

Source: Own calculations from data by NSI, Macroeconomic statistics, GDP - regional level (2016), GDP_1.1.4.xls, and Infostat (2007)

Even more accurate idea of the importance of the four aggregated sectoral groups mainly observe in this region study is obtained by identifying the location quotient (LQ) (11) of each of them in the individual regions (Figure 3).
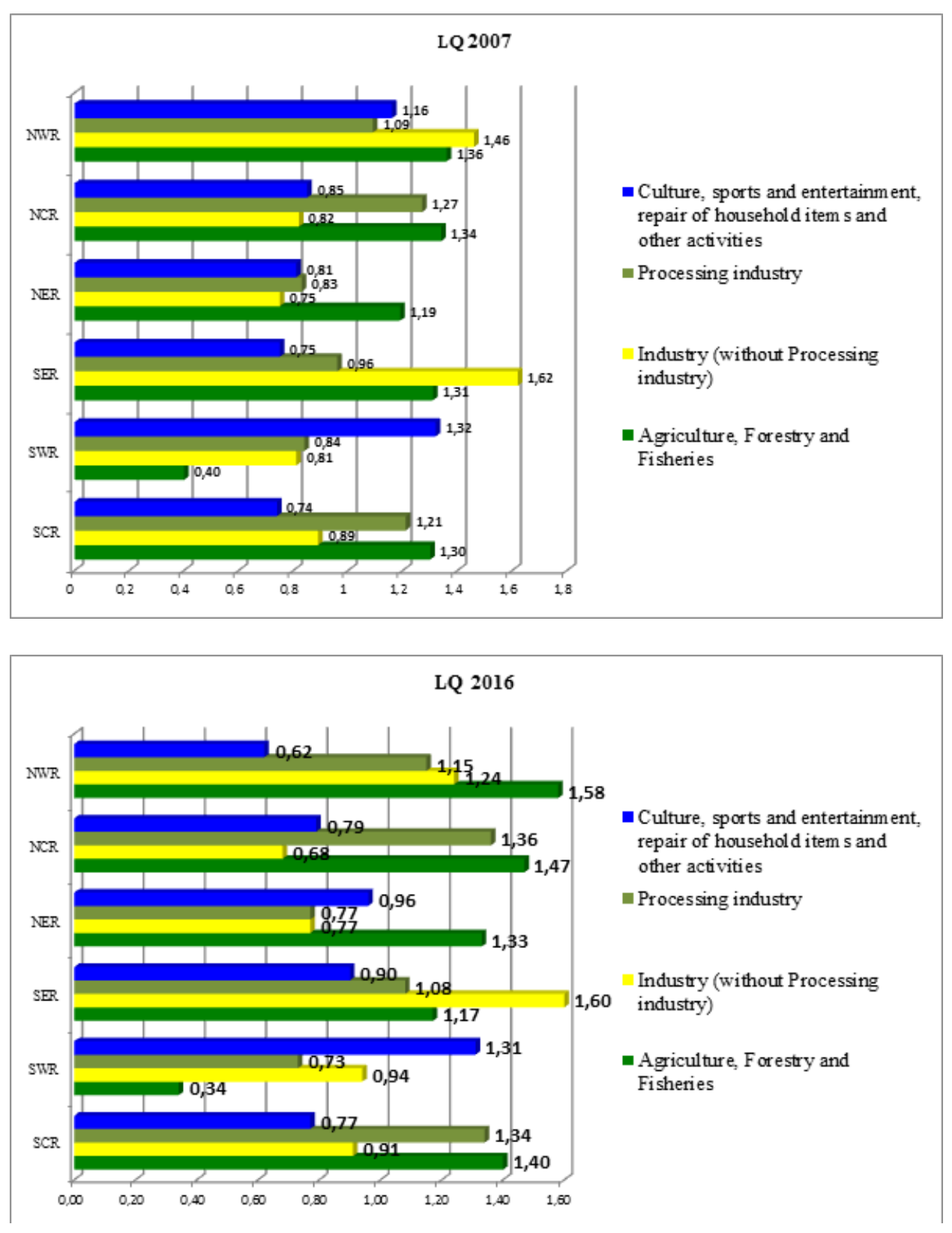

Figure 3. Location quotient of the selected sectors in the NUTS 2 regions, 2007 and 2016 Source: Own calculations and graphic presentation 
What immediately stands out is the value of LQ of the Agriculture, Forestry and Fisheries sector both at the beginning and at the end of the period it is higher than 1.00 (excluding the SWR), even an increase in LQ of the sector (except for the SWR and SER). If in 2007, in half of the regions this sector is leading by LQ value (NCR, NER, SCR), then in 2016, in four regions "agriculture, forestry and fisheries" became the leading one, including NWR in that group. This is a strong signal that the regions (with the exception of the capital city) in Bulgaria have the potential to use as a leading direction in bioeconomy the "Agriculture, Forestry and Fisheries" sector, with the regions of northern Bulgaria having higher potential advantages. Cycling nutrients or primary production related to the provision of food, raw materials or resources, just as climate regulation and waste decomposition require unimpeded operation of major environmental processes (services). In this respect, taking account of socio-economic needs in a regional aspect can help develop locally traditional livelihoods. For example, the empowerment of fishing communities around the Danube River and an open dialogue on local needs and the problems they face would ensure good cooperation and guarantee their rights of access to fishing resources and fishing areas.

Here, however, we can outline two problems - on the one hand, as a whole, the agricultural sector in the country creates low added value and, on the other hand, research and development and achievements in in the field of bioeconomy require better developed cluster, networking and partnership relations in order to implement a proactive policy of applying more bioresources and products on a bio- and biophysical basis in subsequent stages of the production chain, including through the implementation of the principles of the circular economy. The processing industry also demonstrated regional benefits in four of the six regions (NWR, NCR, SER, SCR), with the LQ value in all four regions being higher than 1.00 and rising in 2016 compared to 2007. Industry (without the processing industry) has major advantages in the SER and NWR, which requires further studies at a lower level of aggregation in order to identify the specific economic activities that are users of bioeconomic resources or are part of a sustainable bio-based economy, i.e. to identify which activities in the relevant region have localizing advantages. Although the value of LQ of the sector Culture, sports and entertainment, repair of household items and other activities was below 1.00 in 2016 (with the exception of the SWR where the capital city belongs), it is noteworthy that in the Black Sea regions (NER and SER) it is close to one (0.96 and 0.90 , respectively), with a reported increase in the quotient in 2016 compared to 2007. This means that this sector needs special attention in the NER, SER and SWR, given its ever stronger integration for the sustainable bioeconomy and the needs of regional smart specialization. In the area of culture, the relationship between the development of the regional economy and the bioeconomy is ambiguous and dynamic. Specific aspect is the relationship between agriculture and cultural heritage. For example, the Local Initiative Group in the town of Rakovski, district of Pazardzhik develops a project related to conservation and valorisation of the specific local rural cuisine, with its typical quality and naturalness. Interesting is the project "Say cheese! Balkan Cheese", related to the creation of a common Balkan cheese and cheese brand and marketing of dairy products, incl. developing a "Cheese Path" to include 10 partners from at least 5 Balkan Peninsula countries. Interesting is also the first cross-border business incubator for ecotourism and organic farming (How the EU changes rural areas, No. 2, December 2018) developed by Lyaskovets municipality (District of Veliko Tarnovo) in partnership with the Romanian municipality Videle. The locally organized culinary festivals have long been part of local development plans. They encourage the production of fruits and vegetables from typical local varieties with certain taste, nutritional qualities and ecological purity. Among these are Smilyan Bean Fest, Cherry Fest in Kyustendil, Sevlievo Pumpkin Fest, Watermelon Fest in Salmanovo (Shumen district), etc. Such distinctive forms of traditional livelihood and crafts are preserved in many regions of the country. Based on a long-term partnership with the European Parliament and the European Commission through joint programs, as well as with UNESCO and the World Tourism Organization (UNWTO), the Council of Europe is building a number of cultural routes across EU countries, incl. Bulgaria. Within the context of regional economy and bioeconomy, interesting are: The Iter Vitis Route; The Road of the Vine (vine and wine landscapes certified, 2009); Route of Roman Emperors and Danube Wine (Certified in 2015)

The Ministry of Economy and Energy presents results about the regional specialization in 2014 in some sectoral activities (12), including the Processing industry. Regional specialization in "Food production" shows the most prominent is the SWR, followed by the SCR and NCR.

The present study also determines the contribution of each of the regions to the employment in the selected four sectors (Figure 4). Figure 4 shows that in 2016 the 
largest contribution to the employment in Agriculture, Forestry and Fisheries has the SCR $(26.32 \%)$ and the lowest SWR $(12.28 \%)$. In the processing industry sector, the largest contributor is the SWR $(26.33 \%)$ and the smallest is for the NER (9.56\%). For employment in Industry (excluding processing industry) the highest is the contribution of SWR $(33,83 \%)$, and the lowest that of the $\operatorname{NCR}(7,11 \%)$.

Thus, the reported share of each region in the total employment in the selected sectors on a national level is also characterized by dynamics compared to 2007. Figure 5 shows that the strongest absolute (in percentage points) positive change was observed for the SWR (Culture, sports and entertainment, repair of household items and other activities), followed by the SCR (Processing industry sector), and in relative terms the positive change is the highest for the SWR (26\% - Industry sector (without Processing industry), followed by NER (19\% - "Culture ...") and in third place were the SCR (12\% Processing industry sector) and the BER (12\% Agriculture, Forestry and Fisheries sector). By overall decrease in the contribution to employment in all four selected sectors are characterized the NWR and the NCR, with the strongest decrease in the NWR. In the Agriculture, forestry and fisheries sector, with the largest decrease in the contribution, is the SER, and in the "Processing industry" the most unfavourable is the tendency in the SWR.

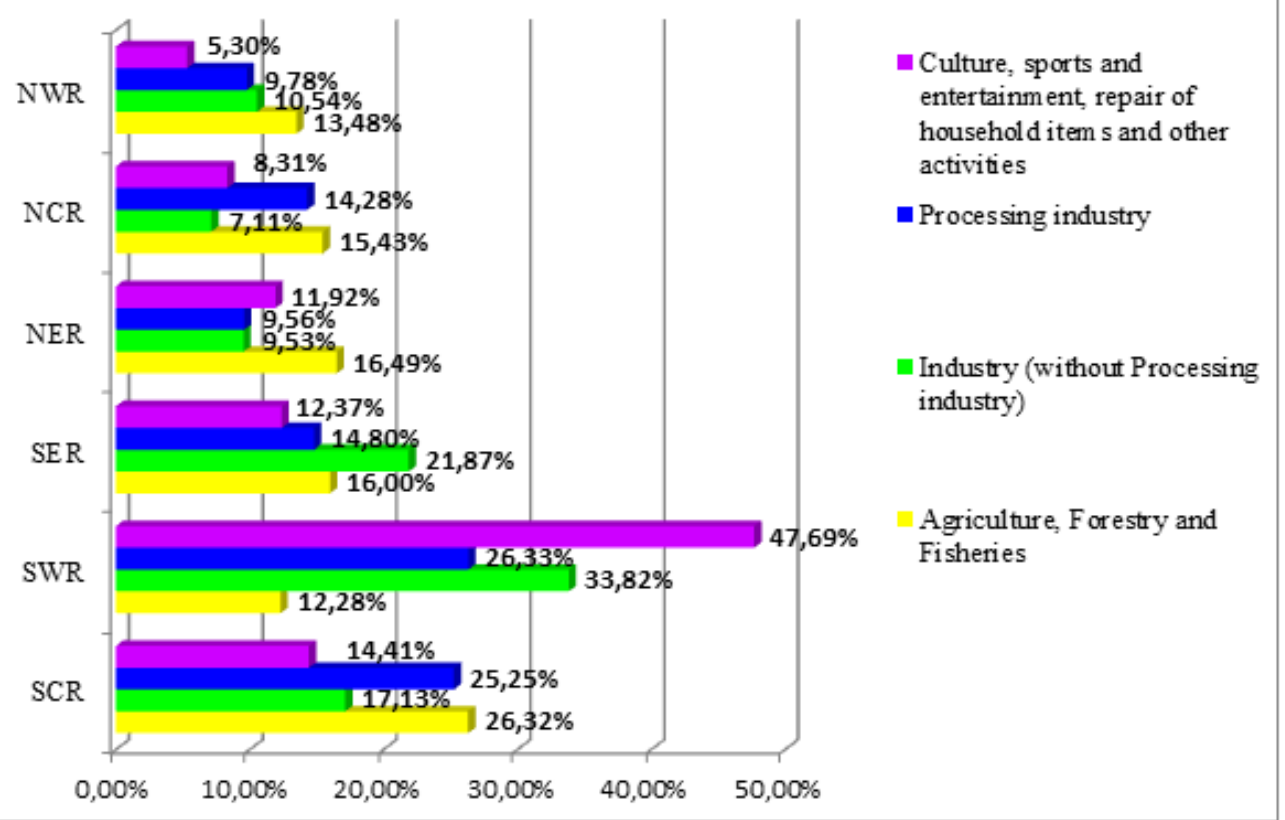

Figure 4. Share of employment by sectors in the regions compared to the number of employed people in the same sector in the country for 2016

Source: Own calculations and graphic presentation

For proactive attitude and exploiting the potential for development of bioconomy activities, it is important to have scientific research and applied activities in support of bioeconomy. The Innovative Strategy for Smart Specialization (13) defines four thematic areas of innovation combined with regional specialization: information and communication technologies; mechatronics and clean technologies; healthy life industries and biotechnology (including foods); new technologies in creative and recreational industries.

R\&D in the field of natural, medical, agricultural and technical sciences is considered leading for bioeconomy. The regional specialization in "R\&D in the field of natural, medical, agricultural and technical sciences" presented by the Ministry of Economy and Energy (14) shows that the leading region is the SWR with about $76 \%$ of the employed in that economic activity being concentrated there. The lowest employment rate is represented in the NER, while the remaining regions provide between $4 \%$ and $6 \%$ of the employment in this R\&D. These disproportions are among the obstacles facing the regional bioeconomy.

Both in the „Innovation strategy for smart specialization" and in the context of a bio-based economy, the approach to economic development should be based on targeted support for identified technological niches that are promising for the region, presenting interest for the business to invest and undoubtedly with provided human potential needed. 
YARKOVA Y., et al.

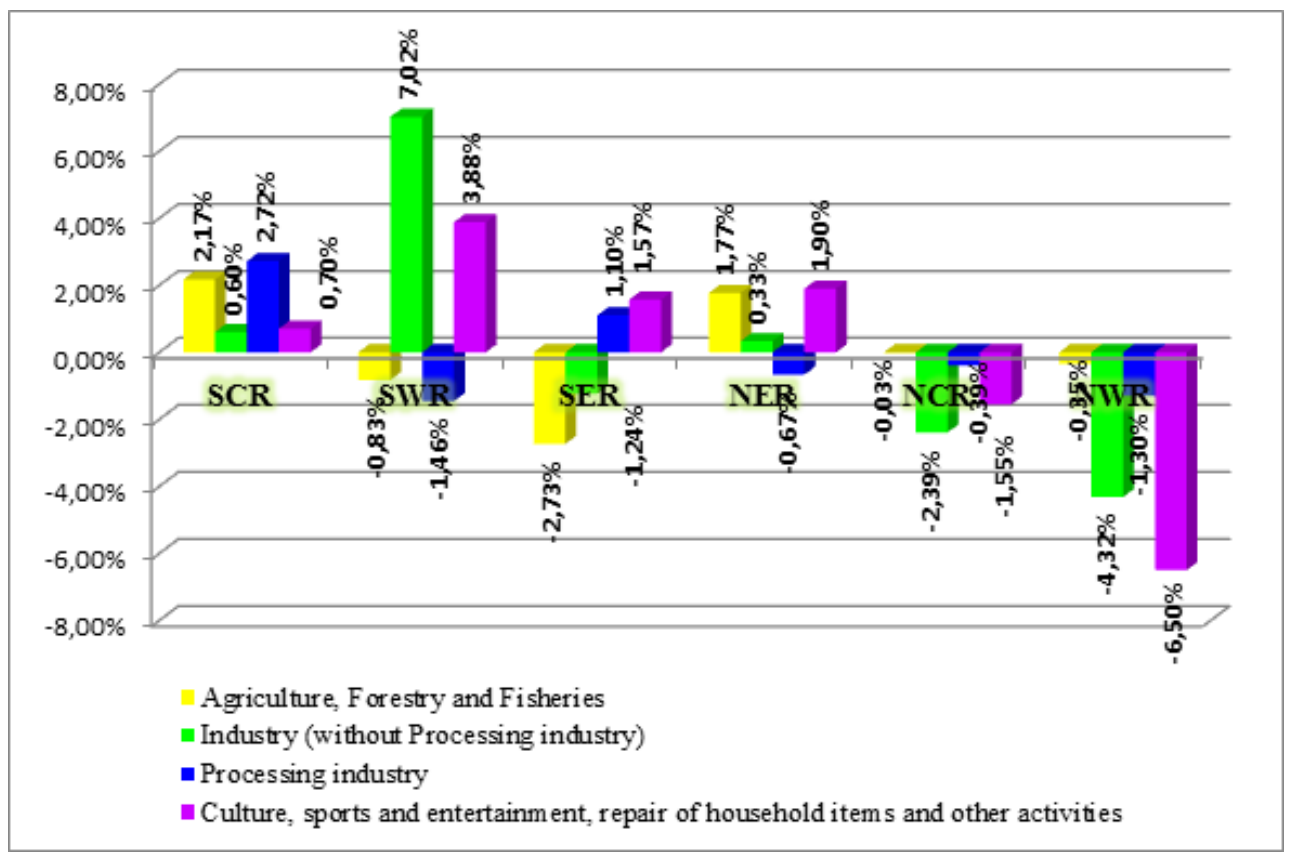

Figure 5. Dynamics in the share of employed people by sectors in the regions compared to the number of employed people in the same sector in the country - 2016 compared to 2007

Source: Own calculations and graphic presentation

\section{CONCLUSION}

Within the EU, a policy has been developed and pursued explicitly aimed at transforming the economy into pillars based on renewable resources and sustainability. Moreover, the attention of all national and regional authorities is attracted by the real practical actions taken in the field of sustainable bioeconomy.

Biological resources and their functions are the leading renewable components of the sustainable business model pursued by the policy and practice of growth and development of bioeconomy, which is why sectors which are a $100 \%$ organic business sector need special attention and support at a national and regional level to achieve the objectives of sustainable development and the circular economy.

Key findings on the analysis of the contribution of primary consumers and/or producers of biological resources in the regional economy of the six NUTS2 regions in Bulgaria can be summarized as follows:

In 2016 (the last of the ten-year period observed) in the regions of Bulgaria (with the exception of the capital city region) the biopotential of the economy is obvious given the leading employment in the sectors Agriculture, Forestry and Fisheries and Processing industry.

The unfavorable fact of reducing the absolute number of employed in Agriculture, Forestry and Fisheries in all regions, mainly as a result of deepening problems in the demographic characteristics of the population does not affect negatively the value of its location quotient (still it is higher than 1.00) and even an increase all regions of Northern Bulgaria and in The SCR has been recorded.

An interesting result of the analysis is also that the SWR and the SER demonstrate an increased contribution of the agrarian sector to the GVA, which provokes the need for a deeper study of the potential of the respective components of bioeconomy and support the deployment of those which can participate in the smart and sustainable specialization.

The share of young people in agriculture has grown which is a potential for introducing innovative and political measures for supporting the increasing the role of bioeconomic production in the regions concerned.

In the monitored period, the Processing industry and Industry (excluding Processing industry) sectors, most regions limit their contribution to the number of employees, respectively in the development of bio-based activities. However, the processing industry demonstrated regional advantages in four of the six regions (NWR, NCR, SER, SCR). The established benefits of Industry (without Processing industry) in the SER and NWR need further studies at a lower level of aggregation to identify the specific economic activities that are part of a sustainable biobased economy. 
The authors' statement on the need for special attention to the sector "Culture, sport and entertainment, repair of household items and other activities" is due to the observed growth both in the relative share and in the absolute number of employees and the fact that, along with the SWR location advantages are typical of the Black Sea regions as well (NER and SER). In addition, successful practices of intergration between agri-food sector and cultural and historical heritage have been developed.

Given the need to identify and develop regional niches for bioeconomy, there is a need to elaborate regional statistical system for the bio-economic sector in order to provide adequate and up-to-date information. Regarding the researched sectors and their contribution to the bioeconomic orientation of the regional economy, it is important to undertake real actions to support the development of cluster, network and partner relationships to implement a proactive policy of applying more bioresources and products on a bio- and biophysical basis in the different stages of the production chain.

\section{ACKNOWLEDGEMENT}

We wish to acknowledge the support of National Scientific Program "Healthy Foods for Strong Bioeconomics and Quality of Life" of the Ministry of Education and Science, Bulgaria funding our work on developing the article.

\section{REFERENCES}

1. COM (2012) 60, 2012, Innovations for sustainable growth: bioeconomy for Europe, 13.2.2012

2. $\operatorname{SWD}(2017) 374,2012$, Review of the 2012 European Bioeconomy Strategy, 13.11.2017

3. Denis de Rougemont, 1997, "The Future is our Affair", Zlatorog Publishing House, ISBN 954-437-048-X

4. Lehtonen, O. \& Okkonen, L. Regional socio-economic impacts of decentralised bioeconomy: a case of Suutela wooden village, Finland, Environ Dev Sustain (2013) February 2013, Volume 15, Issue 1, pp 245-256 https://doi.org/10.1007/s10668012-9372-6

5. Thomas G. Johnson, Ira Altman, Rural development opportunities in the bioeconomy, Biomass and Bioenergy 63, XXX April, 2014, 341-344

6. European Commission, 2018, A sustainable bioeconomy for Europe: strengthening the links between the economy, society and the environment, Communication from the Commission to the European Parliament, the Council, the European Economic and Social Committee and the Committee of the Regions, Brussels, 11.10.2018, $\operatorname{COM}(2018), \quad 673$ final https://eurlex.europa.eu/legalcontent/EN/TXT/PDF/?uri=CELEX:52018 DC0673\&from $=E N$

7. Formas (The Swedish Research Council for Environment, Agricultural Sciences and Spatial Planning), 2012 Strategy for Research and Innovation for a Social Economy Based on bioproducts

8. D2.1. Database Bioeconomy Products and Processes 2017

9. NSI, Employed and employment rates national level; statistical regions; districts, Infostat,

https://infostat.nsi.bg/infostat/pages/reports/ query.jsf?x_2=864

10.Aleksiev, G., D. Doncheva, K. Stoyanov, K. Stankov, 2018, Factors determining the local consumption of bioproducts in the South-East region (on the example of Stara Zagora), Management and Sustainable Development 2018, No.3, pp. 40-44

11.Hildebrand and Mace, 1950, The employment multiplier in an expanding industrial market: Los Angeles County, 1940-47, Review of Economics and Statistics, vol.32, no.3, pp. 241-249.

12.Ministry of Economy and Energy, 2014, Directorate "Small and Medium-Sized Enterprises and Innovations", Department "Innovation and Entrepreneurship", Production and Export Specialization

13.Innovative Strategy for Smart Specialization of the Republic of Bulgaria 2014-2020

www.mi.government.bg/files/useruploads/fi les/innovations/ris3_26_10_2015_bg.pdf

14.Ministry of Economy, Energy and Tourism, 2013, Regional specialization of the leading innovative activities, classification according to the proposal of the European Commission for the development of the innovation indicator, Innovation and Entrepreneurship Division Decrease "Investments, Innovation and Entrepreneurship" 